\title{
Evaluation of bactericidal and virucidal activity of novel disinfectant Aaride AGT-1 compared to other commercially available disinfectants against hospital-acquired infections (HAIs)
}

\author{
Jindal, H.M. ${ }^{1}$, Chandramathi, S. ${ }^{*}$, Sekaran, S.D. ${ }^{2}$ and Suresh, K. ${ }^{3 \#}$ \\ ${ }^{1}$ Department of Medical Microbiology, Faculty of Medicine, University of Malaya, 50603 Kuala Lumpur, Malaysia \\ ${ }^{2}$ School of Basic Medical Sciences, Faculty of Medicine \& Biomedical Sciences, Mahsa University, \\ 42610 Jenjarom, Selangor, Malaysia \\ ${ }^{3}$ Department of Parasitology, Faculty of Medicine, University of Malaya, 50603 Kuala Lumpur, Malaysia \\ *\#Corresponding author e-mails: chandramathi@um.edu.my; suresh@um.edu.my \\ Received 28 February 2020; received in revised form 12 May 2020; accepted 12 June 2020
}

\begin{abstract}
Hand hygiene is the topmost crucial procedure to prevent hospital-acquired infections. Choosing an effective hand disinfectant is necessary in enforcing good hand hygiene practice especially in hospital settings. The aim of the study was to investigate the efficacy of Aaride AGT-1 as a hand disinfectant for the inhibition of pathogenic microorganisms' transmission among both patients and personnel in the health care system compared to other commercially available disinfectants. In the present study, a new hand disinfectant Aaride AGT-1 was tested against several bacterial and viral pathogens to evaluate its antimicrobial activity profile. The results revealed that Aaride AGT-1 displayed the highest antibacterial activity against five pathogenic bacteria including MRSA when compared to other commercially available hand sanitizers. Aaride AGT-1 showed the lowest percentage needed to inhibit the growth of bacterial pathogens. In addition, results obtained from time killing assay revealed that Aaride AGT-1 demonstrated the best killing kinetics, by eradicating the bacterial cells rapidly within 0.5 min with 6 log reduction (>99.99\% killing). Also, Aaride AGT1 was able to reduce $100 \%$ plaque formed by three viruses namely HSV-1, HSV-2 and EV-71. In conclusion, Aaride AGT-1 is capable of killing wide-spectrum of pathogens including bacteria and viruses compared to other common disinfectants used in hospital settings. Aaride AGT-1's ability to kill both bacteria and viruses contributes as valuable addition to the hand disinfection portfolio.
\end{abstract}

\section{INTRODUCTION}

Nosocomial infections also called hospitalacquired/associated infections (HAIs), are caused by a variety of microbes and they are of great concern for both health care providers and patients under medical care (Santajit \& Indrawattana, 2016). In 2002, a study conducted in the United Stated estimated a total of 1.7 million patients suffered from hospital-acquired infections, and nearly 99,000 deaths caused by or were related to a hospital-acquired infection, making HAI the sixth leading cause of death in the United States (Klevens et al., 2007). Another survey study of hospital-acquired infections (HAI) in the United States in 2011 indicated a total of about 722,000 cases caused by nosocomial infections with the death of 75,000 patients, similar data have been reported from Europe. In Southeast Asia, a systematic review previously conducted on 41 studies revealed that the pooled prevalence of HAIs was 9.0\% (20 cases per 1000 intensive care unit-days) (Ling et al., 2015). According to WHO, the incidence of nosocomial infections in Malaysia is $14 \%$ (WHO, 2011). The growing numbers of 
nosocomial infections place a major burden on healthcare systems and have significant global economic costs. Costs include high mortality and morbidity rates, inefficiencies in hospital capacity and operations, and increased treatment costs. In the United States alone, the estimated impact of HAIs on health care budget is $\$ 5$ billion to $\$ 10$ billion annually.

About one third or more of HAIs are preventable (Stone et al., 2005; Yokoe et al., 2015) as mostly occur due to poor hand hygiene (Pittet et al., 2009). It is well known that hands are the primary route for transmitting microbes to any individuals especially patients at hospital settings (Pittet et al., 1999). Following this, WHO and many other public health organizations have emphasized hand hygiene as the crucial point of measure in preventing HAIs (Pittet et al., 2009).

Generally, HAIs are caused by both bacteria and viruses. Bacteria are the most common cause of hospital-acquired infections. About 90\% of nosocomial infections are caused by bacterial pathogens (Bereket et al., 2012). Some of these bacteria belong to the natural flora of the patient and cause infection only when the immune system of the patient becomes susceptible to infections (Khan et al., 2015). The bacteria that are commonly involved in nosocomial infections include Acinetobacter spp., Streptococcus spp., coagulase-negative staphylococci, enterococci, Pseudomonas aeruginosa, Staphylococcus aureus, Bacillus cereus, Proteus mirabilis, Klebsiella pneumonia, Escherichia coli and Serratia marcescens. Among these enterococci, $P$. aeruginosa, $S$. aureus and $E$. coli are the main causative agents (Horan et al., 2008).

Besides bacteria, viruses also play a significant role in nosocomial infections. Approximately $5 \%$ of all the hospitalacquired infections are caused by viruses (Khan et al., 2017). Viruses can be transmitted through hand-mouth, respiratory route and fecal-oral route (Aitken \& Jeffries, 2001). Enterovirus 71 (EV71) is one of the leading causative agents of hand, foot and mouth disease (HFMD). In recent years, HFMD has been recognized as an emerging public health issue, particularly in the AsiaPacific region (Li et al., 2017). The first major EV71 epidemic in the Asia-Pacific region occurred in 1997 in Malaysia and caused 41 child deaths. Since then, widespread epidemics of EV71 have been reported in several Asia- Pacific countries including Taiwan, Australia, China, Singapore, Vietnam and Cambodia, and have led to many mortalities (Lee, 2016). EV71 can be spread via contaminated hands; either directly from vesicles on the hands, secretions from the oropharynx, or feces (Lee, 2016).

Herpes simplex viruses are among the most prevalent causative agents of viral infections in humans affecting up to $90 \%$ of adults globally (Marchi et al., 2017). The main way of transmission for herpes type 1 (HSV-1) is via oral route with the virus present in sores, saliva and surfaces in or around the mouth. HSV-1 can also be spread to the genital area via oral-genital contact and causes genital herpes, however, most of the genital cases are caused by HSV-2 (Meadows \& Saux, 2004). HSV-2 infection is usually contracted via sexual contact and symptoms include sores around genitals or rectum. Most importantly, both HSV-1 and HSV-2 can be transmitted even if sores are not present (Ramachandran \& Kinchington, 2007).

Therefore, hand sanitization with proper hand disinfectant is necessary especially after being in contact with infected patients. Numerous types and brands of hand disinfectants are currently available in drugstores and some of them are being used in hospital settings upon approval by National Food and Drug Administration (FDA) agencies. It is well-known that each of these agents have varying level of effectiveness. Some of them, upon long-term usage, may even lose their potency against commonly acquired microorganisms that are known for mutative drug-resistant characteristics. Therefore, choosing the best hand disinfectant has always been the necessary step and challenge for regulatory authorities in enforcing good hand hygiene practice for preventing HAIs.

In this study we evaluated the antimicrobial activities of new disinfectant agent, Aaride AGT- $1{ }^{\circledR}$, in comparison with 
other commercially available agents against several bacterial and viral pathogens. Unlike the commonly used hospital disinfectants, Aaride AGT- ${ }^{\circledR}$ disinfectant contains plant based phytoserum (Aaride J.A. International Inc.) and is known not only for its protective effect via formation of a thin liquid barrier on the skin surface, but also has dermal tolerance or less skin irritant effects (unpublished data). Thus, the main aim here is to compare its ability to kill commonly acquired viruses and bacteria compared to five routinely used disinfectants.

\section{MATERIALS AND METHODS}

\section{Hand disinfectants}

For assessing the antimicrobial activity against a wide-range of microbial pathogens, Aaride AGT- ${ }^{\circledR}$ and five different disinfectants namely Betadine ${ }^{\circledR}$, Dettol ${ }^{\circledR}$, Hydrogen peroxide, Lysol ${ }^{\circledR}$ and Softa-Man ${ }^{\circledR}$ were used in this study. Aaride AGT-1 contains phytoserum rejuvenator, ethanol, Robicus Mph Ext in propan-1-ol, n-propanol. Betadine contains povidone-iodine $10 \%$ (W/V). Dettol has chloroxylenol 4.8\% (W/V). Softa-Man contains ethanol (45 g) and propanol-1-ol (18 g) per $100 \mathrm{ml}$ solution as active ingredients. Hydrogen peroxide contains hydrogen peroxide $6 \%$ as active ingredient and diluted with equal amount of water before using as disinfectant Lysol consists of alkyl $\left(50 \% \mathrm{C}_{14}, 40 \% \mathrm{C}_{12}, 10 \% \mathrm{C}_{16}\right)$ dimethyl benzyl ammonium chlorides as active ingredient.

\section{Bacteria and culture conditions}

Five bacterial pathogens Staphylococcus aureus ATCC 29213, Methicillin-resistant Staphylococcus aureus (MRSA) (clinical isolate), Escherichia coli ATCC 25922, Klebsiella pneumoniae (clinical isolate) and Pseudomonas aeruginosa ATCC 27853 were selected to test their sensitivity to all six disinfectants. All the bacterial strains were cultured on Mueller-Hinton ( $\mathrm{MH}$ ) agar overnight at $37^{\circ} \mathrm{C}$ prior to any experiment. For determining the minimum inhibitory concentration (MIC), cationally adjusted
Mueller-Hinton broth (MHB) was used according to CLSI guidelines. All bacterial strains were obtained from University of Malaya Medical Centre (UMMC).

\section{Viruses and cell cultures}

Enterovirus 71 (EV71), herpes simplex virus type 1 (HSV-1), and herpes simplex virus type 1 (HSV-2) were obtained from University of Malaya Medical Center (UMMC) and used in this study to perform the plaque assay. The test virus suspensions were prepared by infecting monolayers of the Vero cell line (ATCC ${ }^{\circledR}$ CCL-81 ${ }^{\mathrm{TM}}$ ). Vero cells were grown in Dulbecco's Modified Eagle Medium (DMEM), supplemented with 10\% heat inactivated fetal bovine serum (FBS) and incubated at $37^{\circ} \mathrm{C}$ with $5 \% \mathrm{CO}_{2}$. Viral propagation was conducted by overlaying test viruses on Vero cells monolayer in DMEM supplemented with 10\% FBS and incubated for $2 \mathrm{hr}$, rocking every 15 mins at $37^{\circ} \mathrm{C}$ with $5 \% \mathrm{CO}_{2}$ for virus adsorption. Five days postinfection, supernatant containing viruses were collected to determine the virus titer by plaque assay or kept at $-80^{\circ} \mathrm{C}$ as virus stock. HSV-1, HSV-2 and EV-71 (without disinfectants) induced cytopathic effect and formed plaques in Vero cells. The titer of the viruses was $7.2 \times 10^{5} \mathrm{pfu} / \mathrm{ml}, 5.6 \times 10^{5}$ $\mathrm{pfu} / \mathrm{ml}$ and $1.2 \times 10^{5} \mathrm{pfu} / \mathrm{ml}$, respectively.

\section{Broth microdilution assay}

The minimum inhibitory concentration (MIC) of the six disinfectants was determined by broth microdilution protocol as indicated by the CLSI guidelines (Clinical and Laboratory Standards Institute, 2012). Briefly, bacterial strains were grown for $18-24 \mathrm{hr}$ at $37^{\circ} \mathrm{C}$. Direct suspension of the colonies were made in cationically adjusted Müeller-Hinton broth (CAMHB) and adjusted to $\mathrm{OD}_{625}$ 0.08-0.1 which corresponds to $1 \sim 2 \times 10^{8}$ CFU/ml followed by serial ten-fold dilutions to give $1 \times 10^{6} \mathrm{CFU} / \mathrm{ml}$. Bacterial suspension ( $50 \mathrm{\mu l}$ ) were added to 96 -well round bottom microtiter plates containing equal volume of disinfectants at different concentrations (50\%, 25\%, 12.5\%, 6.25\%, 3.125\%, 1.56\%, 0.78\% and $0.39 \%)$. The 96 -well plates were incubated for 24 hours at $37^{\circ} \mathrm{C}$. The minimum 
inhibitory concentration (MIC) is defined as the lowest concentration of extract that completely inhibits growth. Minimum bactericidal concentration (MBC) was determined by sub-culturing the test dilutions on to a fresh Müeller-Hinton agar plate and incubated further for 18-24 hr. The first dilution that yielded no bacterial growth on agar plate was taken as MBC.

\section{Time killing assay}

Time killing assay was used to evaluate the killing kinetics of the disinfectants as previously described (Jindal et al., 2015). Briefly, bacterial strains were grown overnight on Muller Hinton Agar (MHA). Direct suspension of the colonies was made in Muller-Hinton Broth (MHB) and adjusted to $\mathrm{OD}_{625}$ 0.08-0.1 which corresponds to $1 \sim 2$ $\mathrm{x} 10^{8} \mathrm{CFU} / \mathrm{ml}$ followed by serial ten-fold dilution to give $1 \times 10^{7} \mathrm{CFU} / \mathrm{ml}$. Hundred $\mu \mathrm{l}$ of bacterial suspension was added to 900 $\mu \mathrm{l}$ of (100\% concentration) of the tested disinfectant to give a final volume of $1 \mathrm{ml}$ with the cell number of $1 \times 10^{6} \mathrm{CFU} / \mathrm{ml}$. All the bacterial suspensions were incubated at room temperature for $(0.5 \mathrm{~min}, 1 \mathrm{~min}, 5$ $\mathrm{min}, 10 \mathrm{~min}$ and $20 \mathrm{~min}$ ). The suspensions were then centrifuged and plated on MHA for cell counting.

Plaque assay to assess anti-viral activity Plaque assay was performed as previously described with slight modification (Chang et al., 2013). To perform the plaque assay, respective cell monolayers were prepared in six-well plates. After the monolayers had been washed with phosphate-buffered saline, serial 10-fold dilutions of the virus were added onto cells and incubated for 2 hours with and without disinfectants (negative control), rocking plates every 15 mins at $37^{\circ} \mathrm{C}$ with $5 \% \mathrm{CO}_{2}$ for virus adsorption. Unabsorbed viruses were removed, and each well was covered with $1 \%$ agarose overlay medium. Following a 5-day incubation period, the monolayers were washed with phosphatebuffered saline and fixed with $4 \%$ formalin for 30 mins and stained with $0.4 \%$ trypan blue. Excess stained was removed from plate and plaques were counted in each well after drying.

\section{RESULTS}

\section{Minimum inhibitory/Bactericidal concentration (MIC/MBC)}

The broth microdilution assay was used to assess the antibacterial activity of Aaride AGT-1 along with other commercially available disinfectants. The results revealed that Aaride AGT-1 had the strongest antibacterial activity compared to other tested disinfectants. At a concentration of 0.78\%, Aaride AGT-1 showed a potent antibacterial activity by inhibiting the growth of $S$. aureus, MRSA and E. coli. At concentration of $1.56 \%$, Aaride AGT-1 inhibited the growth of $K$. pneumoniae and $P$. aeruginosa. In addition, Aaride AGT-1 demonstrated a bactericidal effect at a concentration of $6.25 \%$ against $S$. aureus, MRSA, and E. coli and at concentration of $12.5 \%$ against $K$. pneumoniae and $P$. aeruginosa as none of the tested bacteria were able to grow after plating them on Muller-Hinton agar (Table 1). The minimum inhibitory/bactericidal concentrations (MICs/MBCs) of all tested disinfectants against five nosocomial bacteria are listed in Table 1.

\section{Killing kinetics of disinfectants}

The antibacterial activity of the disinfectants was further assessed by analyzing their killing kinetics against nosocomial bacteria. The killing kinetic results indicated that Aaride AGT-1 displayed rapid bactericidal action towards all five bacterial species. Aaride AGT-1 was able to cause 100\% reduction in the viability of bacterial cells within 30 seconds of incubation (Figure 1). Similar results were obtained when bacterial cells were incubated with Betadine, Lysol and the positive control Softa-man (Figure 1). On the other hand, hydrogen peroxide $6 \%$ has failed to eliminate the bacterial cells of $S$. aureus, MRSA and P. aeruginosa up to 20 min of incubation. However, it was able to reduce the number of $E$. coli and $K$. pneumoniae to $4 \times 10^{5}$ and $6 \times 10^{5}$, respectively. Dettol was able to eradicate $S$. aureus, $K$. pneumoniae, and $P$. aeruginosa after 10 min of incubation, MRSA and E. coli after 20 and $5 \mathrm{~min}$, respectively. 
Table 1. Minimum inhibitory concentrations (MICs) and minimum bactericidal concentration (MBC) of Aaride AGT-1 and other disinfectants against five different nosocomial pathogens

\begin{tabular}{lccccc}
\hline & \multicolumn{5}{c}{$\mathrm{MIC}^{\mathrm{a}} / \mathrm{MBC}^{\mathrm{b}}(\%)$} \\
\cline { 2 - 6 } Disinfectant & S. aureus & $\begin{array}{c}\text { Methicillin-resistant } \\
\text { S. aureus (MRSA) }\end{array}$ & E. coli & K. pneumoniae & P. aeruginosa \\
\hline Aaride AGT-1 & $0.78 \% / 6.25 \%$ & $0.78 \% / 6.25 \%$ & $0.78 \% / 6.25 \%$ & $1.56 \% / 12.5 \%$ & $1.56 \% / 12.5 \%$ \\
Betadine & $6.25 \% / 25 \%$ & $6.25 \% / 25 \%$ & $12.5 \% / 50 \%$ & $6.25 \% / 25 \%$ & $6.25 \% / 25 \%$ \\
Dettol & $100 \% / \mathrm{ND}$ & $100 \% / \mathrm{ND}$ & $100 \% / \mathrm{ND}$ & $50 \% / \mathrm{ND}$ & $50 \% / \mathrm{ND}$ \\
Hydrogen & $\mathrm{ND} / \mathrm{ND}$ & $\mathrm{ND} / \mathrm{ND}$ & $\mathrm{ND} / \mathrm{ND}$ & $\mathrm{ND} / \mathrm{ND}$ & $\mathrm{ND} / \mathrm{ND}$ \\
peroxide & $1.56 \% / 12.5 \%$ & $1.56 \% / 12.5 \%$ & $1.56 \% / 12.5 \%$ & $3.125 \% / 25 \%$ & $3.125 \% / 12.5 \%$ \\
Lysol & $25 \% / 100 \%$ & $25 \% / 100 \%$ & $12.5 \% / 50 \%$ & $12.5 \% / 50 \%$ & $12.5 \% / 50 \%$ \\
Softa-Man & & & &
\end{tabular}

${ }^{a}$ MIC: Minimum inhibitory concentration.

${ }^{\mathrm{b}}$ MBC: Minimum bactericidal concentration.

${ }^{\mathrm{c}} \mathrm{ND}$ : Not detected.
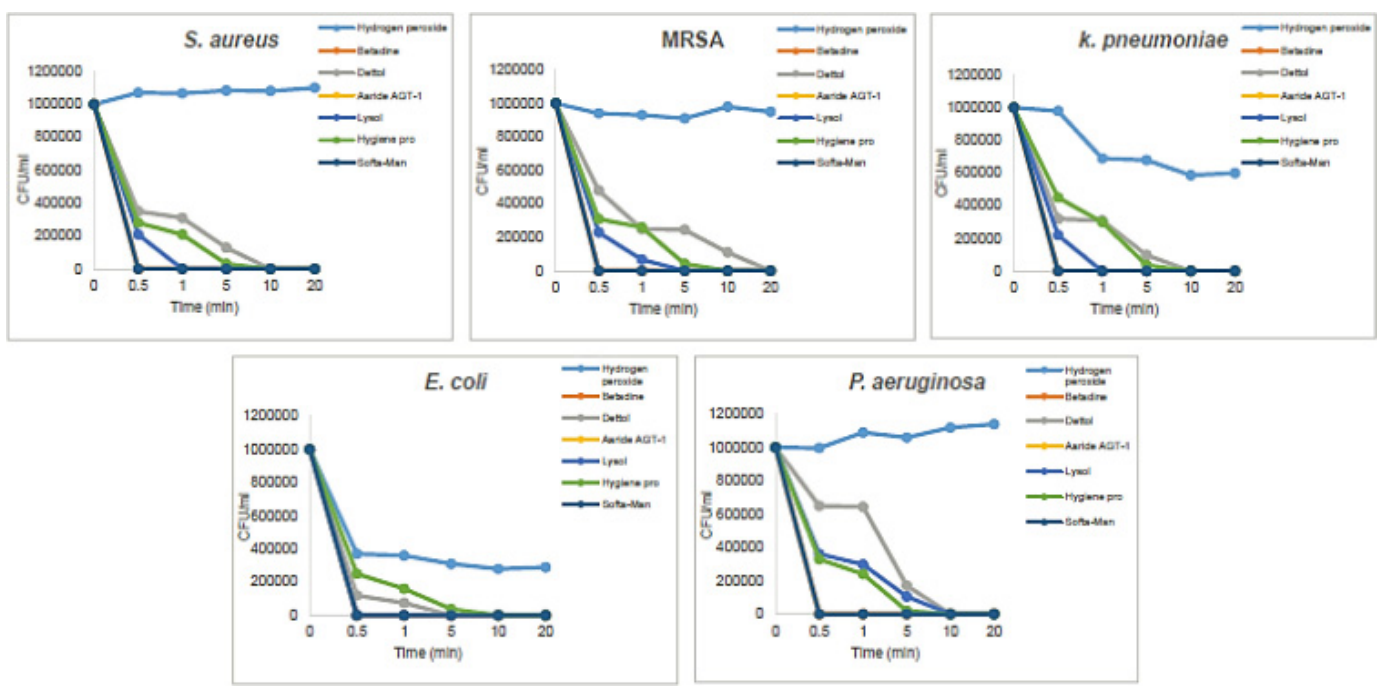

Figure 1. Killing kinetics of Aaride AGT-1 and six other disinfectants against five bacterial strains, (A) S. aureus, (B) MRSA, (C) K. pneumoniae, (D) E. coli and (E) P. aeruginosa. Aaride AGT-1 shows robust killing kinetics by eliminating $100 \%$ of the bacterial cells within 0.5 of incubation.

Table 2. Antiviral activities of five disinfectants against HSV-1, HSV-2 and EV-71

\begin{tabular}{lccc}
\hline Disinfectant & HSV-1 & HSV-2 & EV-71 \\
\hline Aaride AGT-1 & $100.0 \%$ & $100.0 \%$ & $100.0 \%$ \\
Betadine & $75.0 \%$ & $94.6 \%$ & $91.7 \%$ \\
Dettol & $76.4 \%$ & $83.9 \%$ & $91.7 \%$ \\
Hydrogen peroxide & $61.1 \%$ & $92.9 \%$ & $100.0 \%$ \\
Softa-Man & $41.7 \%$ & $83.9 \%$ & $83.3 \%$ \\
\hline
\end{tabular}

\section{Anti-viral activity}

Table 2 summarizes the anti-viral activities of 5 disinfectants, where the results are presented in percentage of plaque reduction compared to the untreated wells (cells with viruses but without disinfectants). Lysol caused long term toxicity to the cells whereby after 4 days of incubation, most of 
the cells were dead, hence we could not assess the anti-viral activity for this disinfectant. On the other hand, Aaride AGT1 showed the strongest antiviral activity against all tested disinfectants by eliminating $100 \%$ of the plaque formed by viruses as shown in figures included in Table 3, 4 and 5. Moreover, Aaride AGT-1 did not cause toxic effect to vero cells after five days of incubation as the cells remain attached to the wells (Table 3, 4 and 5).

\section{DISCUSSION}

In 2004, The World Health Organization (WHO) launched the global hand hygiene (HH) program to decrease healthcare associated infections (HAIs) and enhance patient safety (Pan et al., 2013). Hand hygiene is widely accepted as a simple and inexpensive yet an effective way to reduce nosocomial infection in hospitals, including intensive care units (ICUs), and hospital acquired infections are often viewed as indication of poor acquiescence with hand washing recommendations (Salama et al., 2013). The use of hand sanitizers is gaining popularity both among medical and nonmedical personnel. In the present study, the bactericidal and virucidal activity of Aaride AGT-1 against several bacterial and viral pathogens that cause nosocomial infections was evaluated in comparison with other hand disinfectants. Our results clearly showed that Aaride AGT-1 even at very low concentration $(0.78125 \%$ and $1.56 \%)$ was able to inhibit the growth of five bacterial pathogens responsible for nosocomial infections including MRSA. In addition to its low MIC, Aaride AGT-1 revealed a rapid killing kinetics against all five bacteria indicating that this disinfectant has a potent bactericidal activity by killing all bacterial cells within $30 \mathrm{sec}$ of incubation, which prevent the bacteria from adapting the disinfectant. The robust and rapid bactericidal activity of Aaride AGT-1 is probably due to the incorporation of other active ingredients along with alcohol. The active components of Aaride AGT-1 are ethanol and n-propanol. Alcohols, in particular ethanol (ethyl alcohol), isopropanol and n-propanol are well known to be effective antimicrobial agents. Alcohols display rapid broad-range antimicrobial activity against vegetative bacteria (including mycobacteria), viruses and fungi. It is generally believed that alcohols kill microorganisms by causing membrane damage and rapid denaturation of proteins, leading to interfering with metabolism and cell lysis (Mcdonnell \& Russell, 1999). In addition to alcohols, Aaride AGT-1 contains citric acid, this organic acid has been shown previously to possess antibacterial activity against several bacterial pathogens (Gao, 2012). Moreover, polyethylene glycol which is one of Aaride AGT-1 components has also displayed antibacterial activity against several bacterial strains (Nalawade et al., 2015). In addition, we have observed that the phytoserum contained in Aaride AGT-1 did not cause irritation on skin and confers a healthy barrier (unpublished data). We believe that all these ingredients together cause Aaride AGT-1 to possess a strong and rapid bactericidal activity.

In addition to the bactericidal activity, Aaride AGT-1 also revealed a robust virucidal activity by inactivating both enveloped and non-enveloped viruses namely HSV and EV-71. Previous studies have shown that non-enveloped viruses can be inactivated with ethanol alone in concentrations above $80 \% \mathrm{v} / \mathrm{v}$ (Ionidis et al., 2016). Human EV-71 was only inactivated by $95 \%$ ethanol and not by $70 \%$ and $75 \%$ ethanol or any concentration of isopropanol (Chang et al., 2013). The strong virucidal activity of Aaride AGT-1 is probably a result of ethanol and propanol mixture. Organic acids such as citric acid is active against enveloped but not against nonenveloped viruses on their own. Previous study has shown that the activity of $70 \%$ ethanol solution against non-enveloped FCV improved from $2.6 \log _{10}$ to $>4.4 \log _{10}$ reduction when the $\mathrm{pH}$ of the solution is dropped from 7.4 to 3.0. Citric acid has exposed a virucidal ability against rhinovirus at artificially contaminated hands. Moreover, our results revealed that Aaride AGT-1 was safer than other disinfectants namely Lysol as it was highly toxic towards 
Table 3. Antiviral activities of disinfectants against HSV-1 in Vero cells

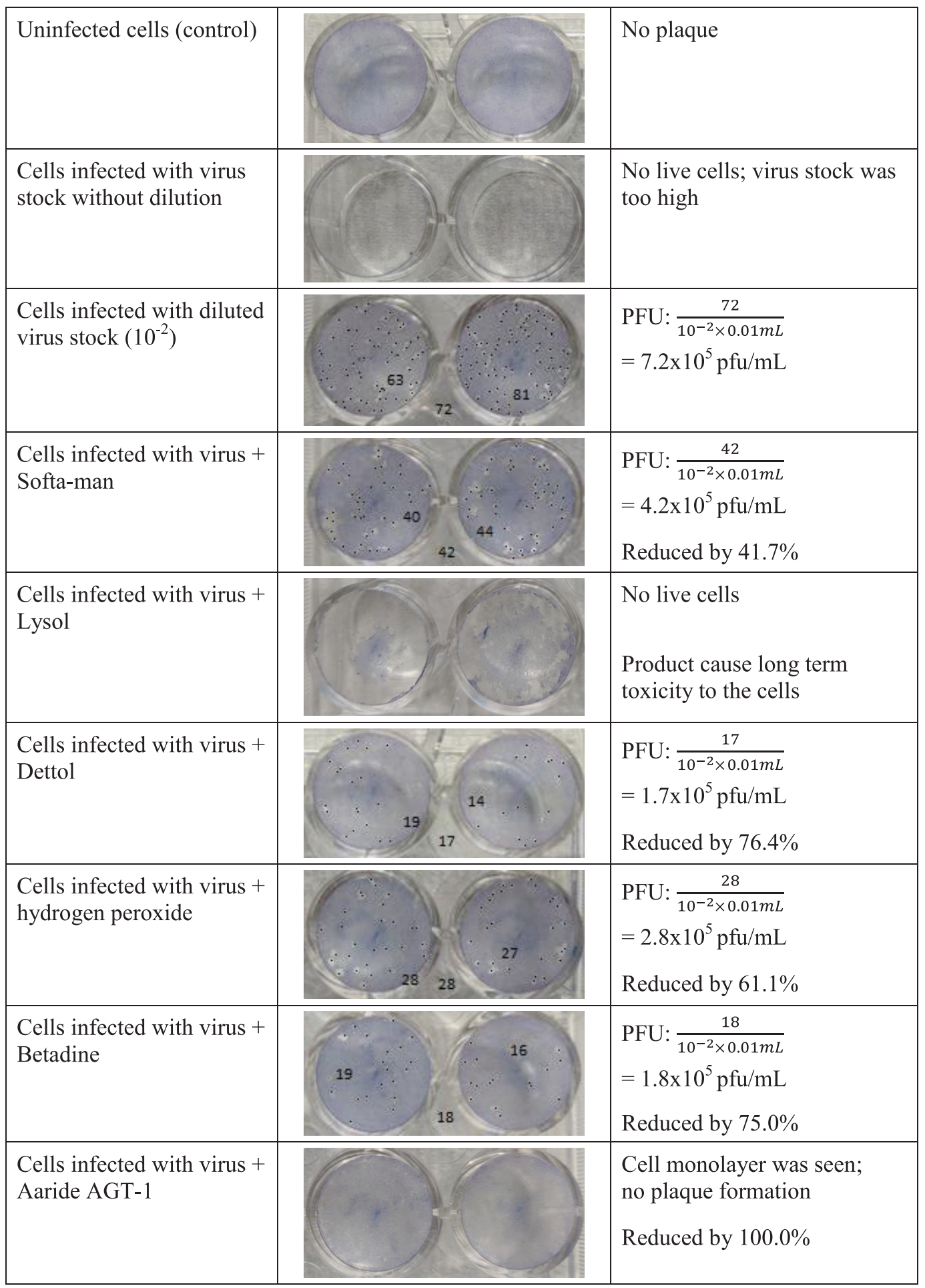


Table 4. Antiviral activities of disinfectants against HSV-2 in Vero cells

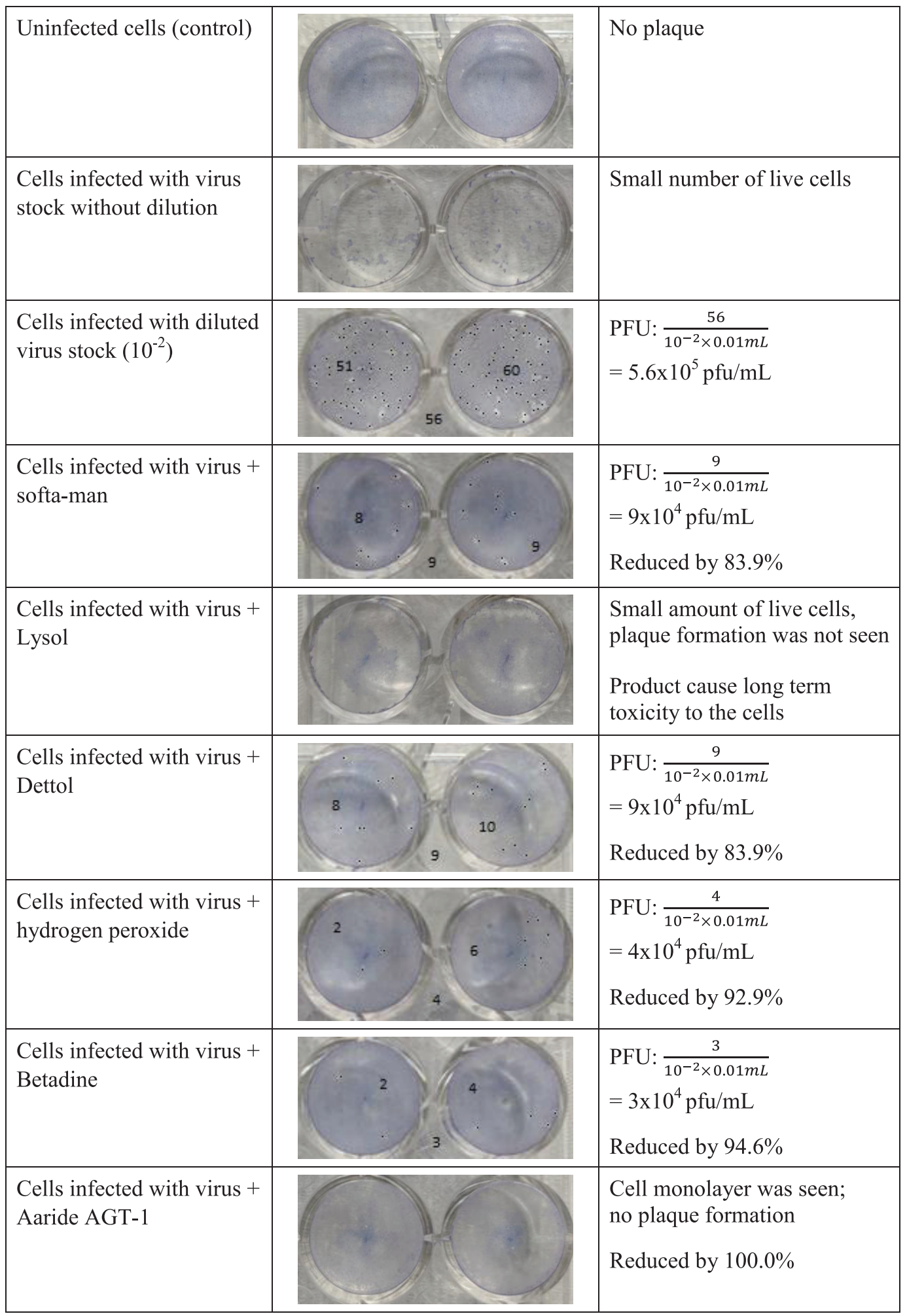


Table 5. Antiviral activities of disinfectants against EV71 in Vero cells

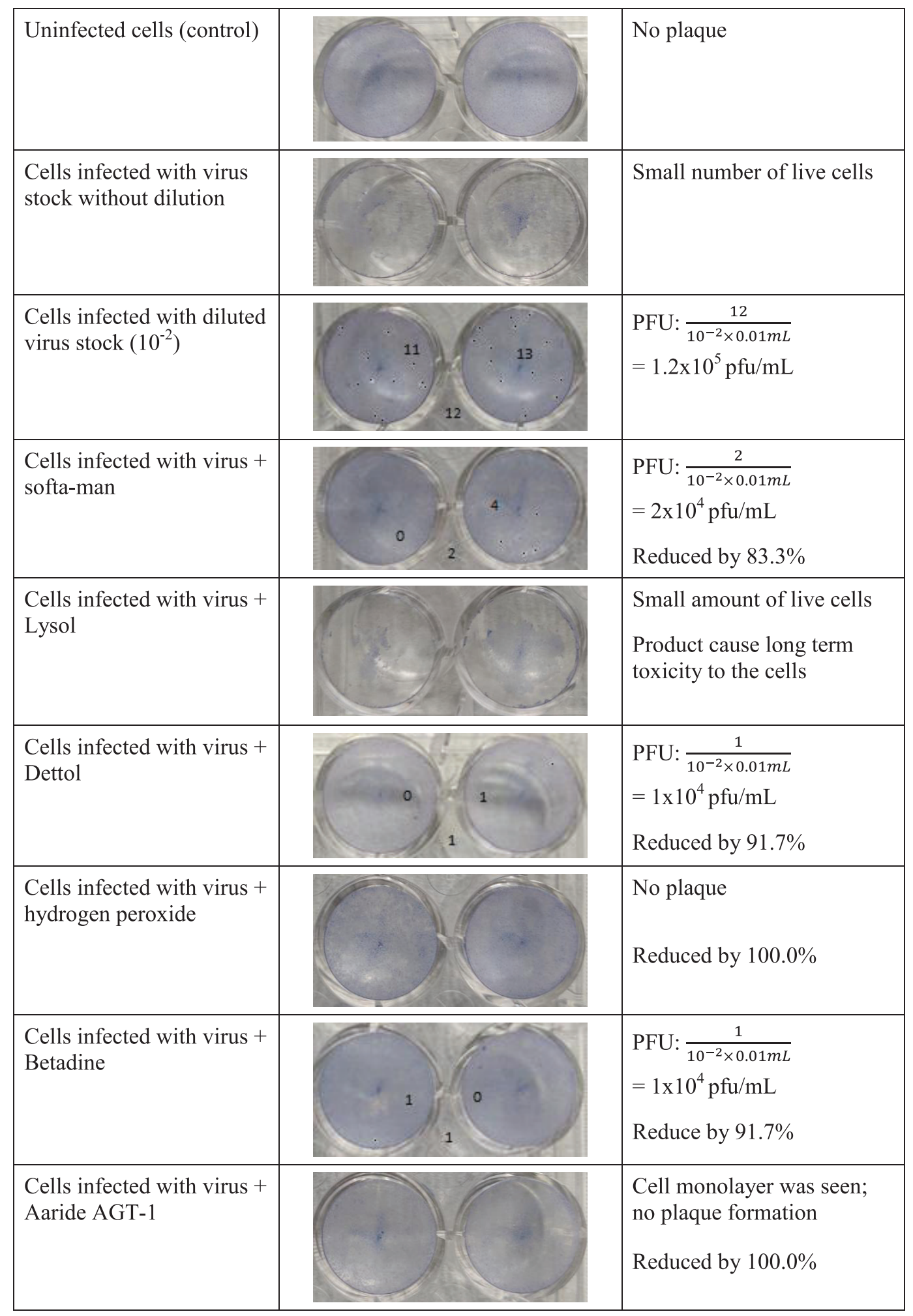


Vero cells and caused death after 4 days of incubation.

In conclusion, Aaride AGT-1 with its unique formulation of ethanol, propanol and citric acid is capable of inactivating enveloped and non-enveloped viruses tested in this study as well as five different types of bacteria responsible for nosocomial infections. Although it is not possible to test the activity of Aaride AGT-1 against each bacterium and virus however, the tested microorganisms in this study are representatives for the wide spectrum of relevant and commonly acquired pathogens that are directly or indirectly transferred by human hands. Therefore, we believe that this disinfectant will certainly be a beneficial addition to the hand disinfection portfolio.

Acknowledgement. We would like to thank Dr. Soe Hui Jen for repeating and validating anti-viral related experiment.

\section{Funding}

This study was supported by TRGS grant TRGS/1/2018/UM/01/7/3.

\section{Transparency declarations}

None to declare.

\section{Competing Financial Interests}

The authors declare no competing interests.

\section{Conflict of Interest}

The authors declare no conflict of interest.

\section{REFERENCES}

Aaride, J.A. International Inc. (https://www. aarideonline.biz/products; accessed on $23^{\text {rd }}$ April, 2020).

Aitken, C. \& Jeffries, D.J. (2001). Nosocomial spread of viral disease. Clinical Microbiology Reviews 14: 528-46.

Bereket, W., Hemalatha, K., Getenet, B., Wondwossen, T., Solomon, A., Zeynudin, A. \& Kannan, S. (2012). Update on bacterial nosocomial infections. European Review for Medical and Pharmacological Sciences 16: 10391044.
Chang, S.C., Li, W.C., Huang, K.Y., Huang, Y.C., Chiu, C.H., Chen, C.J., Hsieh, Y.C., Kuo, C.Y., Shih, S.R. \& Lin, T.Y. (2013). Efficacy of alcohols and alcohol-based hand disinfectants against human enterovirus 71. Journal of Hospital Infection 83: 288-293.

Clinical and Laboratory Standards Institute. (2012). Methods for Dilution Antimicrobial Susceptibility Tests for Bacteria That Grow Aerobically/; Approved Standard - Ninth Edition (Ninth Edit, Vol. 32). Wayne, Pennsylvania: Clinical and Laboratory Standards Institute.

Gao, Z. (2012). Evaluation of different kinds of organic acids and their antibacterial activity in Japanese Apricot fruits. African Journal of Agricultural Research 7: 4911-4918.

Horan, T.C., Andrus, M. \& Dudeck, M.A. (2008). CDC/NHSN surveillance definition of health care-associated infection and criteria for specific types of infections in the acute care setting. American Journal of Infection Control 36: 309-332.

Ionidis, G., Hübscher, J., Jack, T., Becker, B., Bischoff, B., Todt, D., Hodasa, V., Brill, F.H.H., Steinmann, E. \& Steinmann, J. (2016). Development and virucidal activity of a novel alcohol-based hand disinfectant supplemented with urea and citric acid. BMC Infectious Diseases 16: 77.

Jindal, H.M., Le, C.F., Yusof, M.Y.M., Velayuthan, R.D., Lee, V.S., Zain, S.M., Isa, D.M. \& Sekaran, S.D. (2015). Antimicrobial activity of novel synthetic peptides derived from indolicidin and ranalexin against Streptococcus pneumoniae. PLoS ONE 10: e0128532.

Khan, H.A., Ahmad, A. \& Mehboob, R. (2015). Nosocomial infections and their control strategies. Asian Pacific Journal of Tropical Biomedicine 5: 509-514.

Khan, H.A., Baig, F.K. \& Mehboob, R. (2017). Nosocomial infections: Epidemiology, prevention, control and surveillance. Asian Pacific Journal of Tropical Biomedicine 7: 478-482. 
Klevens, R.M., Edwards, J.R., Richards, C.L., Horan, T.C., Gaynes, R.P., Pollock, D.A. \& Cardo, D.M. (2007). Estimating Health Care-Associated Infections and Deaths in U.S. Hospitals, 2002. Public Health Reports 122: 160-166.

Lee, K.Y. (2016). Enterovirus 71 infection and neurological complications. Korean Journal of Pediatrics 59: 395-401.

Li, B., Yue, Y., Zhang, Y., Yuan, Z., Li, P., Song, N., Lin, W., Liu, Y., Gu, L. \& Meng, H. (2017). A Novel Enterovirus 71 (EV71) Virulence Determinant: The 69th Residue of 3C Protease Modulates Pathogenicity. Frontiers in Cellular and Infection Microbiology 7: 1-12.

Ling, M.L., Apisarnthanarak, A. \& Madriaga, G. (2015). The burden of healthcareassociated infections in southeast Asia: A systematic literature review and meta-analysis. Clinical Infectious Diseases 60: 1690-1699.

Marchi, S., Trombetta, C.M., Gasparini, R., Temperton, N. \& Montomoli, E. (2017). Epidemiology of herpes simplex virus type 1 and 2 in Italy: A seroprevalence study from 2000 to 2014. Journal of Preventive Medicine and Hygiene 58: E27-E33.

Mcdonnell, G. \& Russell, A.D. (1999). Antiseptics and disinfectants: Activity, action, and resistance. Clinical Microbiology Reviews 12: 147-179.

Meadows, E. \& Saux, N. Le. (2004). A systematic review of the effectiveness of antimicrobial rinse-free hand sanitizers for prevention of illnessrelated absenteeism in elementary school children. BMC Public Health 4: 1-11.

Nalawade, T., Sogi, S.P. \& Bhat, K. (2015). Bactericidal activity of propylene glycol, glycerine, polyethylene glycol 400, and polyethylene glycol 1000 against selected microorganisms. Journal of International Society of Preventive and Community Dentistry 5: 114.
Pan, S.C., Tien, K.L., Hung, I.C., Lin, Y.J., Sheng, W.H., Wang, M.J., Chang, S.C., Kunin, C.M. \& Chen, Y.C. (2013). Compliance of Health Care Workers with Hand Hygiene Practices: Independent Advantages of Overt and Covert Observers. PLoS ONE 8: $1-7$.

Pittet, D., Allegranzi, B. \& Boyce, J. (2009). The World Health Organization Guidelines on Hand Hygiene in Health Care and Their Consensus Recommendations. Infection Control \& Hospital Epidemiology 30: 611-622.

Pittet, D., Dharan, S., Touveneau, S., Sauvan, V. \& Perneger, T.V. (1999). Bacterial Contamination of the Hands of Hospital Staff During Routine Patient Care. Archives of Internal Medicine 159: 821.

Ramachandran, S. \& Kinchington, P.R. (2007). Potential prophylactic and therapeutic vaccines for HSV infections. Current Pharmaceutical Design 13: 1965-1973.

Salama, M.F., Jamal, W.Y., Mousa, H. Al, AlAbdulGhani, K.A. \& Rotimi, V.O. (2013). The effect of hand hygiene compliance on hospital-acquired infections in an ICU setting in a Kuwaiti teaching hospital. Journal of Infection and Public Health 6: 27-34.

Santajit, S. \& Indrawattana, N. (2016). Mechanisms of Antimicrobial Resistance in ESKAPE Pathogens. BioMed Research International 2016: 2475067.

Stone, P.W., Hedblom, E.C., Murphy, D.M., Miller, S.B. \& Homan, L. (2005). The economic impact of infection control: Making the business case for increased infection control resources. American Journal of Infection Control 33: 542-547.

WHO, W.H.O. (2011). Report on the Burden of Endemic Health Care-Associated Infection Worldwide Clean Care is Safer Care.

Yokoe, D.S., Anderson, D.J., Berenholtz, S.M., Calfee, D.P., Dubberke, E.R., Ellingson, K.D., Gerding, D.N., Haas, J.P. \& Kaye, K.S. (2015). Infections in Acute Care Hospitals/: 2014 Updates 35: 967-977. 